\section{The Final Consultation: The Autopsy}

\section{Khaldoon Aljerian*}

Department of Pathology, Forensic Medicine unit, College of Medicine, King Saud University, Saudi Arabia

\begin{abstract}
Background: Autopsy is an important tool for diagnosis, quality control, teaching and final consultation.

Objective: To correlate morphological diagnoses with the clinical diagnoses and determine the clinical relevance of postmortem diagnoses.

Methods: This retrospective study included 108 consecutive autopsies over 1 year in the autopsy department at Toronto General Hospital in Toronto, Ontario, Canada. Diagnostic discrepancies were categorized using a modified version of Goldman's criteria.

Results: From the 108 autopsies studied, 44 (40.7\%) major missed diagnoses (class I and II) were identified. Of those, $12(11.1 \%)$ were class II and not clinically significant, but $32(29.6 \%)$ were class I. In $21(19.4 \%)$ of those cases, the missed cause of death was related to the primary (previously diagnosed) disease (subclass lb) but in 11 $(10.2 \%)$ of the 108 patients, the discrepancy was due to an entirely new diagnosis (sub class la). As well, $32(29.6 \%)$ missed minor diagnoses were identified.

Conclusion: Autopsy continues to provide new information that is relevant and potentially life-saving. Medical management should not be considered complete until a postmortem examination-the final consultation-has been performed.
\end{abstract}

\section{Introduction}

Autopsy has long been an important tool for education, maintaining the quality of patient care and the final consultation. In addition to its other benefits, autopsy has been used to provide or modify treatments for future generations of patients; train young physicians; and provide definitive answers about the efficacy of treatments administered [1]. Countries are struggling to keep this rich tool of medicine alive and a revival of autopsy has been called for by many pathologists $[2]$.

However, rates of autopsy have declined over recent years because of changing legislation, challenges with informed consent, and

*Corresponding author: Khaldoon Aljerian, Department of Pathology, Forensic Medicine Unit, College of Medicine, King Saud University, Saudi Arabia, Tel: +966 555494649; Email: khaldoonaljerian@gmail.com

Citation: Aljerian K (2017) The Final Consultation: The Autopsy. J Forensic Leg Investig Sci 3: 018

Received: February 19, 2017; Accepted: May 16, 2017; Published: June 01, 2017

Copyright: @ 2017 Aljerian K. This is an open-access article distributed under the terms of the Creative Commons Attribution License, which permits unrestricted use, distribution, and reproduction in any medium, provided the original author and source are credited. alterations to medical education [1-18]. Some countries had autopsy-favorable legal systems, such as Belgium, where autopsy rates were approximately $93 \%$, but even in these countries, rates have fallen [10]. Some countries have reported tremendous drops in their autopsy rates: Sweden had an autopsy rate exceeding $90 \%$ in 1979 , but it fell to $22 \%$ by $1995[19,20]$. The reasons for these declines differ from one country to another $[4,5,9]$. In 1990 , new Danish legislation provoked a dramatic drop in autopsy rates, which had already declined from $45 \%$ in 1970 to $35 \%$ in 1980 [21]. In the first half of 1990 , the rate of autopsy in Denmark was $24 \%$, but in the second half of the same year, it had fallen to $16 \%$. In Australia, the rate of adult autopsies declined from $66 \%$ of all deaths in 1992-1993 to 39\% in 2002-2003 [22].

In France, a 1994 bioethics law requiring physicians to inform relatives before performing an autopsy caused an autopsy rate decline from $15.4 \%$ in 1988 to $3.7 \%$ in 1997 [11]. Indeed, one of the most recent problems for autopsy rates is challenges in obtaining informed consent from relatives. In particular, the retention of organs was not made specifically clear to the families of the deceased, as shown in the "Alder Hey Inquiry", in New Zealand and in France [11,13,23]. Physicians (especially junior physicians, who are often left with this task) are challenged in obtaining consent because of their lack of knowledge in this field. This has become an issue more recently, due to a new trend in medical education that no longer encourages attending autopsies. It is difficult for clinicians to obtain consent from families for a procedure they may not understand, have not witnessed or are unfamiliar with.

We need to find ways to communicate the benefits of autopsy and increase rates to previous levels. The University of Texas Medical Branch at Galveston, Texas, reported that the annual autopsy rates from 1981 to 1995 ranged from 45 to 59\% [24]. The authors concluded that their high rates could be attributed to several key factors, including better organization, assignment of duties, internal and external quality control, improved interaction with clinicians and disproving the idea of increased litigation with higher autopsy rates. The Yale University School of Medicine saw an increase in autopsy rates after implementation of a quality improvement program [14,25].

The objective of this study was to correlate morphological diagnoses with clinical diagnoses to evaluate the clinical relevance of postmortem diagnoses.

\section{Methods}

In this retrospective study, I reviewed the records of clinical autopsies conducted by staff pathologists at Toronto General Hospital in Toronto, Ontario, Canada from January to December 1999. Toronto General Hospital is a teaching hospital with 471 beds in the downtown core of Canada's largest city. All full autopsies conducted at the hospital during the study period were included. Autopsies limited to a specific organ or system were excluded.

Using a chart in Excel (Microsoft Corp., Redmond, WA), I collected the following information from each patient's medical record and the autopsy request form: age, sex, clinical cause of death, pathological cause of death, and other clinical and pathological findings. Then, I collected information on major/minor diagnoses and cause of death from the autopsy record.

I compared antemortem and postmortem diagnoses in 108 consecutive deceased patients who underwent autopsy over the study 
period. Most autopsies were conducted within 24 hours of patient death; several were conducted 24 to 48 hours after patient death. Autopsies included external examination and gross and microscopic assessment of all body organs, including the brain and central nervous system.

I categorized discrepancies between ante- and postmortem diagnoses using a modified version of the Goldman criteria, a system for classifying errors in autopsy findings [3]. A new diagnosis revealed during the autopsy that had not been established antemortem was considered a missed diagnosis (Table 1). Classes I and II constituted missed major diagnoses and I subdivided Class I into Ia (caused death but not related to reported antemortem cause of death) and Ib (resulted from/complication of primary cause of death). Classes III and IV were missed minor diagnoses. Patients could have more than one major clinical or missed major diagnosis if the additional diagnosis was relevant to the cause of death. I focused my analysis on class I missed major diagnoses as revealed by autopsy because of the potential clinical significance of missed diagnoses in this class.

\begin{tabular}{|c|c|}
\hline Class & Description \\
\hline I & $\begin{array}{r}\text { Missed major diagnosis that may have led to modification of the pa- } \\
\text { tient's management if it had been known antemortem }\end{array}$ \\
\hline Ia & Caused death but was not related to the antemortem cause of death \\
\hline Ib & $\begin{array}{r}\text { Resulted from, was a complication of, or was due to the primary cause } \\
\text { of death }\end{array}$ \\
\hline II & $\begin{array}{r}\text { Missed major diagnosis that would not have led to modification of the } \\
\text { patient's management if it had been known antemortem }\end{array}$ \\
\hline III & $\begin{array}{r}\text { Missed minor diagnosis that is related to the terminal disease process } \\
\text { but not causing death }\end{array}$ \\
\hline IV & $\begin{array}{r}\text { Missed minor diagnosis, important but unrelated to the terminal disease } \\
\text { process, or contributing to death in a terminally ill patient }\end{array}$ \\
\hline
\end{tabular}

Table 1: Modified Goldman classification system.

Source: Goldman et al., 1983 [3].

Major diagnosis: Disease causing death; Minor diagnosis: Disease not causing death; Missed diagnosis: New diagnosis revealed at autopsy that was not established antemortem.

For statistical analysis, all data were entered into SAS, version 8.2 (SAS Institute, Inc., Cary, NC). I used descriptive statistics to report findings.

\section{Results}

Of the 108 autopsies performed, 58 of the patients were male and 50 were female. Patients' ages ranged from 22 to 84 years, but the majority was 50 to 79 years of age.

Based on the postmortem findings, the most common causes of death were cardiovascular (34.3\%), central nervous system (29.6\%), lung (16.7\%), gastrointestinal (10.2\%), genitourinary (4.6\%), lymphoreticular (3.7\%), and musculoskeletal (0.9\%).

Among the 108 autopsies, I identified 44 (40.7\%) major missed diagnoses (classes I and II). Of those, 12 (11.1\%) were class II and not clinically significant, but 32 (29.6\%) were class I discrepancies that would have had clinical relevance (i.e., they could have led to modifications to the patient's management; Table 2).

The class I discrepancies I identified most often involved the cardiovascular system $(53.1 \%$; $41.2 \%$ of those were class Ia, a completely new diagnosis) and the pulmonary system $(31.3 \% ; 80 \%$ of those were class Ib, related to the primary antemortem cause of death; Table 3 ).

\begin{tabular}{|c|c|}
\hline Class & Autopsies, $\mathbf{n}$ (\%) \\
\hline I & $32(29.6)$ \\
\hline Ia & $11(10.2)$ \\
\hline Ib & $21(19.4)$ \\
\hline II & $12(11.1)$ \\
\hline III and IV & $32(29.6)$ \\
\hline
\end{tabular}

Table 2: Missed diagnoses by class ${ }^{1}$.

Source: Goldman et al, 1983 [3].

'Some of the 108 autopsies had no missed diagnoses, and some had multiple missed diagnoses.

Looking at the class I missed diagnoses from the point of view of etiology of disease (Table 4), I found that the most common etiology was vascular (59.3\%), then infectious disease (21.9\%). Of the vascular diseases, $57.9 \%$ were cardiovascular and $31.6 \%$ were pulmonary embolism.

Among cases categorized as subclass Ia, $11(10.2 \%)$ of the 108 patients (Table 3), had a discrepancy that was due to an entirely new diagnosis. Again, most of these diagnoses were in the cardiovascular system (63.6\%), with lung and central nervous system diseases each representing $18.2 \%$ (Table 4 ).

In $21(19.4 \%)$ of the 108 cases, the missed cause of death was related to the primary disease (diagnosed antemortem) or subclass Ib (Table 3). The most common systems involved were cardiovascular and pulmonary ( $47.6 \%$ and $38.1 \%$ respectively) with $57 \%$ of vascular etiology (Table 4).

Interestingly, in the present study central nervous system lesions comprised $29.6 \%$ of the total cases, but only $6.25 \%$ of class I missed diagnoses. This may have been because clinicians now have a higher yields in diagnosing central nervous system disease in part because of high-tech imaging.

I also identified 32 (29.6\%) missed minor diagnoses (Table 5) [3].

In 5 of the 108 cases, an antemortem diagnosis could not be obtained. In the case with a clinical diagnosis of colon carcinoma, the autopsy was limited to the brain. In 3 of the cases, the clinical diagnosis was psychiatric (schizophrenia $\mathrm{x} 2$, bipolar disease). In the case of mechanical mitral valves, nonspecific pathological diagnoses were found.

\section{Discussion}

Autopsy provides feedback to the physicians involved in patient care about the accuracy of their evaluations and the effectiveness of their treatments. Together, the clinicians and pathologists assess the findings in each case so that future patients can benefit from this information. The importance of autopsy data as a measure of quality control should not be undervalued.

This was a retrospective study with a small sample size, and the study population may be specific to Toronto. It may be difficult to generalize these findings to other locations.

Nevertheless, the findings of the present study were in keeping with findings from other large centers, which found discrepancy rates of 15 to $40 \%$ [2,6,7,26,27]. Despite advances in medical technology, the frequency of major discrepancies between clinical diagnoses and diagnoses based on pathologic findings-including autopsy-has not changed [3]. Discrepancy rates are likely to stay stable, even with 


\begin{tabular}{|c|c|c|c|c|}
\hline \multirow{2}{*}{ System/Location } & \multirow{2}{*}{ Origin } & \multicolumn{2}{|c|}{ Diagnosis } & \multirow[t]{2}{*}{ Class } \\
\hline & & Ante-mortem & Post-mortem & \\
\hline Cardiovascular & Vascular & Post-CABG & Thrombosis from CABG & la \\
\hline Cardiovascular & Vascular & Post-CABG & Thrombosis from CABG & la \\
\hline Cardiovascular & Vascular & Sudden death & Fixed thrombosis, mechanical valve & la \\
\hline Cardiovascular & Vascular & Sudden death & Fixed thrombosis, mechanical valve & la \\
\hline Cardiovascular & Vascular & Sudden death & Fixed thrombosis, mechanical valve & la \\
\hline Pulmonary & Vascular & Sudden death & Pulmonary embolism & la \\
\hline Central nervous & Vascular & Brown Sequard syndrome & Foix-Alajouanine syndrome & la \\
\hline Cardiovascular & Vascular & Post-aortic, mitral and tricuspid valve repair & Myocardial infarction & $\mathrm{lb}$ \\
\hline Cardiovascular & Vascular & Sepsis & Pulmonary embolism & $\mathrm{lb}$ \\
\hline Cardiovascular & Vascular & Post-mitral valve repair & Myocardial infarction & $\mathrm{lb}$ \\
\hline Cardiovascular & Vascular & Post-CABG & Myocardial infarction & $\mathrm{lb}$ \\
\hline Cardiovascular & Vascular & Post-CABG & Myocardial infarction & $\mathrm{lb}$ \\
\hline Cardiovascular & Vascular & Thrombotic thrombocytopenic purpura & Pericardial tamponade & $\mathrm{lb}$ \\
\hline Pulmonary & Vascular & Post-abdominal surgery & Pulmonary embolism & $\mathrm{lb}$ \\
\hline Pulmonary & Vascular & Post-orthopedic surgery & Pulmonary embolism & $\mathrm{lb}$ \\
\hline Pulmonary & Vascular & Post-gynecological surgery & Pulmonary embolism & $\mathrm{lb}$ \\
\hline Pulmonary & Vascular & Post-CABG & Pulmonary embolism & $\mathrm{lb}$ \\
\hline Pulmonary & Vascular & Pulmonary hemorrhage & Pulmonary embolism & $\mathrm{Ib}$ \\
\hline Gastrointestinal & Vascular & Cecal perforation & Myocardial infarction & $\mathrm{lb}$ \\
\hline Cardiovascular & Infectious/vascular & Post-cardiac transplant & Pneumonia and myocardial infarction & $\mathrm{lb}$ \\
\hline Pulmonary & Infectious/vascular & Lymphoproliferative disorder & Pulmonary aspergillosis, pulmonary embolism & $\mathrm{lb}$ \\
\hline Cardiovascular & Infectious & Sudden death & Fibrinous pericarditis, myocardial infarction & la \\
\hline Pulmonary & Infectious & Seizures & Pneumonia & la \\
\hline Central nervous & Infectious & Pontine gemistocytic astrocytoma & Herpes encephalitis & la \\
\hline Gastrointestinal & Infectious & Sepsis & Pseudomembranous colitis & $\mathrm{lb}$ \\
\hline Cardiovascular & Infectious & Post-aortic valve repair & Pericarditis & $\mathrm{lb}$ \\
\hline Pulmonary & Infectious & Post-abdominal surgery & Pneumonia & $\mathrm{lb}$ \\
\hline Genitourinary & Infectious & Post-gynecological surgery; sepsis & Peritonitis & $\mathrm{lb}$ \\
\hline Cardiovascular & Traumatic & Arrhythmia & Right ventricular damage & $\mathrm{lb}$ \\
\hline Cardiovascular & Traumatic & Aortic valve repair & $\begin{array}{l}\text { Coronary artery damage and myocardial } \\
\text { infarction }\end{array}$ & $\mathrm{lb}$ \\
\hline Pulmonary & Traumatic & Lung surgery & Pulmonary artery trauma & $\mathrm{lb}$ \\
\hline Cardiovascular & Degenerative & Sudden death & Myxomatous prolapsed mitral valve & la \\
\hline
\end{tabular}

Table 3: Class I deaths by etiology and diagnosis.

CABG: Coronary Artery Bypass Graft.

advances in medical technology, because of new emerging diseases (HIV, SARS, etc.,) and their complications [28]. Large institutes will continue to be the centers for referral of the more puzzling and more complicated cases. As well, emerging treatments could cause what are now categorized as a class II missed diagnoses but may be categorized as class I in the future.

The finding of a substantial proportion of missed diagnoses in the cardiovascular and pulmonary systems suggests that these systems should always be kept in mind, because clinicians we are still missing many diagnoses in these 2 systems. Using this information to change medical management in the future could improve patients' lives or even lead to cures.

Although autopsy information is important for general medical purposes, occasionally the patient's family benefits directly, for example, when an unsuspected genetic disorder is found so that diagnosis and intervention can help surviving family members. However, the postmortem procedure is not always acceptable to family members because of concerns about their family member's remains. Newer medical procedures are being introduced to address this challenge. Cacchione et al., found that laparoscopic autopsy was much more acceptable for families than conventional methods, resulting in higher consent rates [29]. Laparoscopic autopsies also give surgical residents invaluable training in laparoscopic skills. Other procedures such as MRI are also gaining popularity for autopsy, especially among relatives reluctant to give their consent for religious reasons. However, limitations include the low number of high-tech imaging machines, even among the G7 countries and the willingness of imaging institutes to image corpses and dedicate scanner and radiologist time to this work. As well, radiologists admit that at present the technology is not yet good enough to provide as much detail as a conventional postmortem examination. Still this type of noninvasive imaging is widely 


\begin{tabular}{|c|c|c|}
\hline Diagnosis & Autopsies, $n$ & Class \\
\hline \multicolumn{3}{|l|}{ Infection } \\
\hline Pneumonia & 2 & IV \\
\hline Focal herpetic encephalitis & 1 & IV \\
\hline Septic splenitis & 2 & IV \\
\hline \multicolumn{3}{|l|}{ Cardiovascular and pulmonary } \\
\hline Myocardial infarction & 2 & $\mathrm{IV}^{1}$ \\
\hline Pulmonary embolism & 3 & $\mathrm{IV}^{1}$ \\
\hline Renal infarct & 1 & IV \\
\hline Acute interstitial pneumonitis & 1 & IV \\
\hline \multicolumn{3}{|c|}{ Gastrointestinal and hepatobillary } \\
\hline Diverticulosis & 8 & III \\
\hline Meckel diverticulum & 1 & III \\
\hline Gastric schwannoma & 1 & III \\
\hline Gastric leiomyoma & 1 & III \\
\hline Gastric stromal tumor & 1 & III \\
\hline Hepatic hemangioma & 1 & III \\
\hline Peptic ulcer bleeding & 1 & IV \\
\hline \multicolumn{3}{|l|}{ Other } \\
\hline Prostate adenocarcioma & 1 & IV \\
\hline Thyroid papillary carcinoma & 1 & IV \\
\hline Adrenal cortical adenoma & 1 & III \\
\hline Lung carcinoid & 1 & IV \\
\hline Pituitary adenoma & 1 & IV \\
\hline Acute tubular necrosis & 1 & IV \\
\hline Total & 32 & \\
\hline
\end{tabular}

accepted among Jewish, Christian and Muslim communities [30,31] and is preferable to no postmortem examination at all $[2,17]$.

The final autopsy report should be a multidisciplinary effort that involves the entire health team, including all departments, specialties and subspecialties involved in the patient's care. It is possible that clinicians may take postmortem results personally, as an exam of their competence; they may also try to persuade the pathologist. However, the ultimate word should be the facts found at the postmortem. For this reason, in the present study I relied on the clinical notes-which, from a legal standpoint, should be complete-instead of involving the attending clinician. Another common complaint is that there was no time to complete a full workup of the patient, and this may be true, but it is not a reason not to perform an autopsy. In fact, such cases are more likely to show important missed diagnoses [14].

Death certificates are also major source of statistical data for identifying public health problems, monitoring progress in public health, allocating research funds, and conducting scientific research. For these reasons, clear and complete reporting of the causes of death is very important. Forensic cases should not be ignored, as they also serve as a vital statistical source. According to Kircher and Anderson, "mortality statistics derived from death certificates are the only continuously collected, population-based, disease-related information available in most parts of the world. For this reason, every effort must be made to ensure that the most specific, accurate and complete information regarding cause of death is registered on death certificates [32]". Educated guesses will never be sufficient for mortality statistics [16].

Classifications make information easier to understand and easier to compare (e.g., the scoring system used for histological grading of prostatic adenocarcinoma $[33,34])$. Goldman and colleagues have applied this concept to autopsy by applying a classification system [3].

In this study, I further subdivided that classification, breaking class I into subclasses Ia and Ib. However it is difficult to use the Goldman classification alone to compare results between hospitals, especially with differing autopsy rates between institutions and even between divisions within an institution. A point system in which both the Goldman class and the autopsy rate is taken into consideration could provide a rating of "diagnosis accuracy" and offer a mathematical means of comparing regions' and hospitals' quality of diagnosis.

\section{Conclusion}

Autopsies continue to provide new information that is relevant and potentially life-saving. They are also important learning tools. Nevertheless, in this retrospective study of autopsy reports in a large Canadian hospital, a substantial number of missed diagnoses were found, many of which were clinically significant. Medical management should not be considered complete until a postmortem examination-the final consultation-has been performed. All major clinical services must have regular, pathology-based, mortality rounds. Completion of the death certificate should be taught at multiple levels of medical education, including undergraduate, postgraduate and at the practicing levels.

\section{References}

1. Burton JL, Underwood J (2007) Clinical, educational, and epidemiological value of autopsy. Lancet 369: 1471-1480.

2. van den Tweel JG, Wittekind C (2016) The medical autopsy as quality assurance tool in clinical medicine: dreams and realities. Virchows Archiv 468: 75-81.

3. Goldman L, Sayson R, Robbins S, Cohn LH, Bettmann M, et al. (1983) The value of the autopsy in three medical eras. N Engl J Med 28: 1000-1005.

4. Roberts WC (1978) The autopsy: its decline and a suggestion for its revival. N Engl J Med 299: 332-338.

5. Angrist A (1965) What remedies for the ailing autopsy? JAMA 193:806-808.

6. Cabot RC (1912) Diagnostic pitfalls identified during a study of three thousand autopsies. JAMA 59: 2295-2298.

7. Cameron HM, McGoogan E, Watson H (1980) Necropsy: a yardstick for clinical diagnoses. Br Med J 281: 985-988.

8. Combes A, Mokhtari M, Couvelard A, Trouillet JL, Baudot J, et al. (2004) Clinical and autopsy diagnoses in the intensive care unit: a prospective study. Arch Intern Med 164: 389-392.

9. Hazard JB (1965) The autopsy. JAMA 193: 805-806.

10. Roosen J, Frans E, Wilmer A, Knockaert DC, Bobbaers H (2000) Comparison of premortem clinical diagnoses in critically ill patients and subsequent autopsy findings. Mayo Clin Proc 75: 562-567.

11. Chariot P, Witt K, Pautot V, Porcher R, Thomas G, et al (2000) Declining autopsy rate in a French hospital: physician's attitudes to the autopsy and use of autopsy material in research publications. Arch Pathol Lab Med 124: 739-745.

12. Underwood J (2004) Why we need to revive the autopsy. Eur J Cancer 40: 1463.

13. O'Grady G (2003) Death of the teaching autopsy. BMJ (Clin Res Ed) 327 802-803. 
14. Sinard JH (2001) Factors affecting autopsy rates, autopsy request rates, and autopsy findings at a large academic medical center. Exp Mol Pathol 70: 333343.

15. Bharathi M, Loo C, Venkatesan M, Sharma P, Virender K, et al. (2015) Current status of perceptions towards autopsy and post-mortem examination among medical undergraduate students. O Int J Med Soc Sci 1: 66-71.

16. Bieri U, Moch H, Dehler S, Korol D, Rohrmann S (2015) Changes in autopsy rates among cancer patients and their impact on cancer statistics from a public health point of view: a longitudinal study from 1980 to 2010 with data from Cancer Registry Zurich. Virchows Archiv 466: 637-643.

17. Bassat Q, Castillo P, Alonso PL, Ordi J, Menéndez C (2016) Resuscitating the dying autopsy. PLoS Med 13: 1001927.

18. Turnbull A, Osborn M, Nicholas N (2015) Hospital autopsy: Endangered or extinct? J Clin Pathol 68: 601-604.

19. Lundberg GD, Voigt GE (1979) Reliability of a presumptive diagnosis in sudden unexpected death in adults. The case for the autopsy. JAMA 242: 23282330.

20. Saukko $P$ (1995) Medicolegal investigative system and sudden death in Scandinavia. Nihon Hoigaku Zasshi 49: 458-465.

21. Petri CN (1993) Decrease in the frequency of autopsies in Denmark after the introduction of a new autopsy act. Qual Assur Health Care 5: 315-318.

22. Royal College of Pathologists of Australasia Autopsy Working Party (2004) The decline of the hospital autopsy: a safety and quality issue for healthcare in Australia. Med J Aust 180: 281-285.

23. Burton JL, Wells M (2002) The Alder Hey affair. Arch Dis Childhood 86: 4-7.

24. Haque AK, Patterson RC, Grafe MR (1996) High autopsy rates at a university medical center. What has gone right? Arch Pathol Lab Med 120: 727-732.
25. Sinard JH, Blood DJ (2001) Quality improvement on an academic autopsy service. Arch Pathol Lab Med 125: 237-245.

26. Bauer FW, Robbins SL (1972) An autopsy study of cancer patients. I. Accuracy of the clinical diagnoses (1955 to 1965) Boston City Hospital. JAMA 221:1471-1474

27. Hartveit $F$ (1977) Clinical and post-mortem assessment of the cause of death. J Pathol 123: 193-210.

28. Hwang DM, Chamberlain DW, Poutanen SM, Low DE, Asa SL, et al. (2005) Pulmonary pathology of severe acute respiratory syndrome in Toronto. Mod Pathol 18: 1-10.

29. Cacchione RN, Sayad P, Pecoraro AM, Ferzli GS (2001) Laparoscopic autopsies. Surg Endosc 15: 619-622.

30. Bisset R (1998) Magnetic resonance imaging may be alternative to necropsy. BMJ 317: 1450

31. Bisset RA, Thomas NB, Turnbull IW, Lee S (2002) Postmortem examinations using magnetic resonance imaging: four year review of a working service. BMJ 324: 1423-1424

32. Kircher T, Anderson RE (1987) Cause of death. Proper completion of the death certificate. JAMA 258: 349-352.

33. Gleason D (1977) Histologic grading and clinical staging of carcinoma of the prostate. In: Tannenbaum M (ed.). Urologic Pathology: The Prostate. Lea \& Febiger, Philadelphia, USA, Pg no: 171-197.

34. Gleason DF, Mellinger GT (1974) Prediction of prognosis for prostatic adenocarcinoma by combined histological grading and clinical staging. J Urol 111: $58-64$ 